Transformation Plans: occupational therapists and physiotherapists can support GPs. Br J Gen Pract 2017; DOI: https://doi.org/10.3399/bjgp17X693413.

2. Majeed $A$. Shortage of general practitioners in the NHS. [Editorial]. BMJ 2017; 358: j3191.

3. Saxon RL, Gray MA, Oprescu Fl. Extended roles for allied health professionals: an updated systematic review of the evidence. J Multidiscip Healthc 2014; 7: 479-488.

\section{It's time for GPs to be recognised as the specialists they are}

I would like to comment on the article in the $B M J$ dated 21 October entitled 'It's time for GPs to be recognised as the specialists they are' by Mary McCarthy.

I fully agree with the author that GPs need to be recognised as specialists in family medicine and urge the Royal College of General Practitioners (RCGP) to look into revising the designation for GPs. The main reason why general practice fails to attract newly qualified doctors is the lower status compared with consultants in the hospital due to their designation. GPs in European countries are called 'consultants in family medicine' and have equal status to their peers in hospitals. No such effort to change the title of GPs has been done by the RCGP in the UK. In some countries, such as India and Pakistan, a doctor can practise as a GP straight after their primary qualification, but this is not the case in the UK and the EU, nor in the US and Australia where doctors have to go through further specialisation after primary medical qualification in order to practise family medicine.

GPs are regarded as inferior and having lower qualifications than hospital peers in the UK and abroad, which is completely inappropriate because they need to complete the GP rotation and MRCGP in order to practise as a GP. It is not the workload that is a deterrent to taking up general practice but the status that makes it unattractive for newly-qualified doctors. Therefore, GPs need to be recognised as consultants in family medicine in order to give them equal status to hospital peers and attract newly-qualified doctors into the profession.

Medini Kulkarni,

GP, Swadlincote, Derbyshire.
E-mail: medinikulkarni2lagmail.com

\section{REFERENCE}

1. McCarthy M. It's time for GPs to be recognised as the specialists they are. BMJ Opinion 2017. http:// blogs.bmj.com/bmj/2017/10/09/mary-mccarthy-itstime-for-gps-to-be-recognised-as-the-specialiststhey-are/ (accessed 4 Dec 2017).

\section{Barriers and facilitators to integration of physician associates into the general practice workforce: a grounded theory approach}

We have observed first hand the barriers to integration of physician associates into the general practice workforce described by Jackson and colleagues.' Despite a strong emphasis on primary care within our physician associate course, a paucity of local primary care positions resulted in all but one of our first cohort of qualified physician associates being appointed to posts within two local secondary care trusts.

We have appointed a clinical leadership fellow to work with stakeholders in developing roles for physician associates and we are striving to create an environment in which physician associates become an established part of the primary care workforce.

Since the establishment of secondary care roles for physician associates within the two local trusts, we have observed unprecedented interest from secondary care, with almost all trusts in our area planning to create roles for physician associates. We hope that we will see this process replicated in primary care and that, by developing 'pioneer programmes' to introduce physician associates to the primary care workforce within our region, we can demonstrate to the rest of our general practice colleagues how the barriers to physician associate integration can be managed and that physician associates themselves can become the facilitators of a dynamic, sustainable general practice workforce for the future.

Sam Roberts,

Clinical Leadership Fellow, Health Education
England.

E-mail: sam.robertsahee.nhs.uk

Laura Stroud,

Professor of Public Health and Education Innovation, Director of Student Education for the School of Medicine, Leeds Institute of Health Sciences, University of Leeds.

Helen E Millott,

Programme Lead, PG Diploma Physician Associate Studies, Leeds Institute of Medical Education, University of Leeds.

\section{REFERENCE}

1. Jackson B, Marshall M, Schofield S. Barriers and facilitators to integration of physician associates into the general practice workforce: a grounded theory approach. Br J Gen Pract 2017; DOI: https://doi. org/10.3399/bjgp17X693113.

DOI: https://doi.org/10.3399/10.3399/bjgp17X694061

\section{Corrections}

In the article by Morris E et al. Point-of-care lactate testing for sepsis at presentation to health care: a systematic review of patient outcomes. Br J Gen Pract 2017; DOI: https://doi.org/10.3399/bjgp17X693665, author affiliations were shown incorrectly. We apologise for this error. The online version has been corrected.

\section{DOI: https://doi.org/10.3399/bjgp17X693893}

In the article by de Lima A, et al. Misdiagnosis of a hidden cause of hypertension: a case report. $\mathrm{Br}$ J Gen Pract 2017; DOI: https://doi.org/10.3399/ bjgp17X693869, some text in the print article was obscured by Figures 1 and 2. Under the heading 'Case Report 1', paragraph 2 appeared to end at 'this diagnosis was dismissed.', but should have continued on: ' this diagnosis was dismissed. Thyroid hormones, metanephrines, and cortisol levels were within normal limits, which ruled out the diagnoses of thyroid disease, phaeochromocytoma, and Cushing's syndrome.', and the beginning of paragraph 3 should have started: Surgical oncology was consulted for evaluation of the adrenal mass. Physical exam was normal with the exception of blood pressure (BP) of 149/94 $\mathrm{mmHg}$. Serum potassium was $2.6 \mathrm{mEq} / \mathrm{L}$ despite oral supplementation. Adrenal venous sampling

Under 'Case Report 2', paragraph 1 appeared to end '... spironolactone, potassium chloride,' but should have continued on '... spironolactone, potassium chloride, phentermine, alprazolam, and zolpidem. On examination, the patient was anxious and BP was 144/82 $\mathrm{mmHg}$. Serum potassium was $2.8 \mathrm{mEq} / \mathrm{L}$, despite supplementation. Serum aldosterone was $79 \mathrm{ng} / \mathrm{dL}$, more than twice the normal level. An abdominal MRI showed a $2.2 \times$ $2.1 \mathrm{~cm}$ right adrenal adenoma (Figure 2). Thyroid function, metanephrines, and cortisol levels were normal and cytological studies revealed benign thyroid disease.' We apologise for this error. The online version has been corrected.

DOI: https://doi.org/10.3399/bjgp17X694396 